Vol. 4, No. 1, January 2016

Jurnal llmial

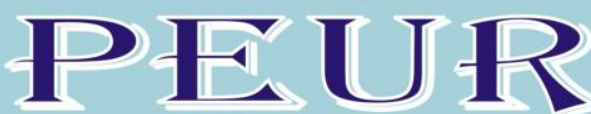

Media Kajian Ilmiah Sosial, Politik, Hukum, Agama dan Budaya
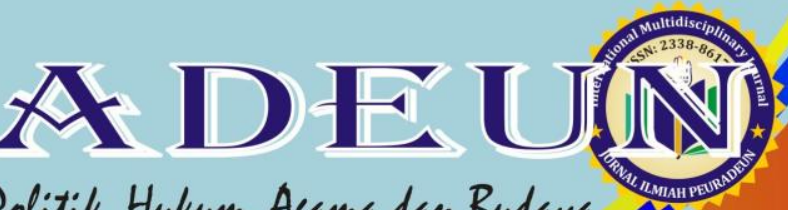


\title{
MULTICULTURAL PERSPECTIVE ON THE MOTIVATION OF STUDENTS IN TEACHING PHYSICAL EDUCATION
}

\author{
${ }^{1}$ Peter Kaylene and ${ }^{2}$ Tressa Lawrence Rosone \\ ${ }^{1}$ State University of New York, New York City, United States \\ 2State University of New York, New York City, United States \\ Email:peter_ky@yahoo.com
}

Received: May 29, 2015

Accepted: July 11, 2015

Published: Jan 21, 2016

Article Url: https://journal.scadindependent.org/index.php/jipeuradeun/article/view/90

\begin{abstract}
With the rollover of a new century, society in America has become more dynamic. These changes in student demographics throughout the U.S. have spawned an increased need for awareness by teachers for their students' needs across curriculums. This study examined attitudes of high school students toward fitness and sports activities taught in physical education, and the perceived effectiveness of their physical education curriculum for improving their fitness and skill levels. This research has focused on providing teachers with multicultural training with the hope that through this training, teachers will convey the importance of respect and sensitivity for all cultures to their students. Overall, successful physical education teachers in the culturally diverse school setting (e.g., urban schools) tend to maintain high expectations for student accomplishment, provide the best possible learning environments, and implement activities that aid increased student involvement.
\end{abstract}

Keywords: Multicultural, Motivation, Physical, Education, Diversity 


\section{A. Introduction}

Multicultural education is considered to be an "education that values diversity and includes the perspectives of a variety of cultural groups on a regular basis" (Santrock, 2001: 171). The goal of multicultural education is to provide equal opportunities for all students through educational experiences that help them to become knowledgeable and respectful of others, making teachers' knowledge and skills extremely important. One of the major goals of multicultural education is to create, within schools and society, the democratic ideals that value justice, equality, and freedom (Banks, 2002). Influential teachers in multicultural education have a firm understanding of all cultures and this helps to ensure that each student receives an equal learning opportunity in the classroom setting (Sparks, Butt, \& Pahnos., 1996).

There is an increasing diversity within the society of the United States, and hence student population in PreK-12 schools, requiring a cadre of teaching professionals who understand and respect diversity. With the rollover of a new century, society in America has become more dynamic. "Our communities are marked for major changes in the coming century as American society becomes more culturally diverse with an ever-increasing ethnic population" (Tannehill, 1993). These changes in student demographics throughout the U.S. have spawned an increased need for awareness by teachers for their students' needs across curriculums. However, while most teachers in the core academic subjects have revamped their curriculum to address the needs or their diverse students, not much research has been conducted to assess those needs and discover a way to address them. As an English as a Second Language (ESL)/ Physical Education teacher I'm cognizant of my students who are new to the U.S. and I try to help their assimilation into our society. Nevertheless, I have not been as devoted to learning about their cultural perceptions towards sports and physical fitness as I have been with ESL. Physical educators... "must be conscious of how young people within various cultures perceive physical education and sport" (Tannehill, 1993).

As stated earlier, research in the field of physical education and multiculturalism has been quite limited. Some researchers such as Joan Duda, 
Darren Treasure and Glyn Roberts have studied how specific pedagogical theories and their applications affect physical education student motivation.

Much research has been conducted on the rationale for a multicultural approach to teaching physical education (Swisher, 1986). This research has focused on providing teachers with multicultural training with the hope that through this training, teachers will convey the importance of respect and sensitivity for all cultures to their students. Amongst all my search for information dealing directly with multicultural students themselves was an article by Deborah Tannehill and Dorothy Zakrajsek. They created a questionnaire to determine their multicultural students' attitudes and beliefs about physical education. Using their research as a jumping off point, I decided to perform my own assessment about the attitudes and beliefs of my own students about physical education.

\section{B. Method}

During the fourth quarter of the 1999-2000 school year at Fairfax County Public Schools, randomly selected ninth and tenth grade classes were surveyed. These students attended Falls Church High School, a school well known for its highly diverse population. There were a total number of 246 students (129 females, 117 males) surveyed from seven different physical education classes. Students were asked to identify their ethnic background. The following indicates the breakdown in ethnicity:

Anglo $(35 \%)-38$ males +48 females $=86$ total

Asian $(25 \%)-28$ males +35 females $=63$ total

Hispanic $(24 \%)-29$ males +29 females $=58$ total

African-American $(9 \%)-13$ males +9 females $=22$ total

Mixed $(7 \%)-9$ males +8 females $=17$ total

Teachers administered a 14-item questionnaire to their students during physical education class. Students completed the questionnaire in approximately 20-30 minutes. The survey contained questions regarding the following categories: demographic information, student motivation, student perceptions about curriculum, physical activity assessment and personal experiences. 
With regard to student motivation, a list of five reasons why students generally like physical education were presented, and students were asked to rank those reasons from 1-5 with a value of " 1 " being the strongest. This list included reasons such as (1) being with friends (2) getting in shape (3) break from the classroom (4) enjoy competing in sports with other students and (5) it's an easy "A." Students were also presented a list of seven general reasons why students don't like physical education and again were asked to rank the reasons from 1-7. This list included reasons such as (1) wearing a uniform (2) appearance for remainder of day (3) no athletic ability (4) don't like competing with students of different ability levels (5) physical activity makes me sick (6) can't communicate with other students and (7) classes are too big.

In assessing students' perceptions regarding values taught and learned through physical education, students were once again presented with a list of seven values and were asked to rank them on a scale of 1 to 7 . Common values listed on the questionnaire were (1) sportsmanship (2) fun and entertainment (3) teamwork (4) competition with other people (5) competition with self (6) stress reduction and (7) interest development in activity.

Next, students were asked to rank their top five favorite activities from a list of 18 activities. In addition, students were also asked to rank their top five least favorite activities of the same list. These rankings were then tabulated to determine trends in general and according to ethnicity.

Finally, students were requested to respond to the following openended statement: Please share an experience you've had in physical education class that you liked or disliked and made you feel either good or bad. Though not all students chose to respond to this section of the questionnaire, some answers will be discussed in this paper.

\section{Understanding Multicultural Education through Concepts of Assimilation and Pluralism}

Overall, two theoretical frameworks are commonly used in the study of multicultural education: assimilation and pluralism. According to Rong and Preissle (2009), research on immigration and education was once dominated by 
the assimilation model, which advocated the elimination of ethnic identity and the reconstruction of an "all American and English-speaking only" immigrant identity. The assimilation paradigm, sometimes called a monocultural perspective, espouses tolerance and acceptance of differences in an effort to uphold the existing social structure and power relations - it shares an image or model of "American culture" in the United States (Cushner, McClelland, \& Safford, 2006; Grant, Elsbree, \& Fondrie, 2004).

Instead of the traditional view of immigrants and ethnic minorities, the consideration of pluralistic perspectives in education and society is paramount, particularly in teacher education and student's schooling. The pluralism paradigm is built upon the philosophical ideas of freedom, justice, equality, equity, and human dignity (Grant, et al., 2004). Under pluralism, ethnic groups can maintain their distinctive cultural identities, which imply recognition of ethnicity as a legitimate way of grouping in the society. The pluralism model accounts for the variety of objectives, processes, or outcomes that are found among different immigrant communities (Rong \& Preissle, 2009).

Through teacher preparation, teachers develop knowledge and understand student diversity, the instructional context in education, and the influence of educational policy in order to improve students' learning experiences and the schooling process. Furthermore, education with a multicultural perspective requires education professionals and teachers to assist students in developing a clear understanding and appreciation of the diverse ethnic and racial groups from pluralistic perspectives (Chepyator-Thomson, 2001). Although there are likely many factors in the school setting that account for differential achievement levels of culturally diverse students, teachers' knowledge and skills that respect pluralistic perspectives are integral to student learning.

Educational agencies in physical education use policy statements to encourage increased involvement in multicultural education. The National Association for Sport and Physical Education (NASPE, 2003a) addressed concepts of multicultural education through standards-based reform strategies that emphasize the importance of respect for others. In context of teaching, 
Standard 5 puts emphasis on the development of a "responsible personal and social behavior that respects self and others in physical activity settings," advocating for students to exhibit this behavior in school physical education. The NASPE (2003b) established the National Standards for Beginning Physical Education Teachers, which advocates standards-based teacher education and teaching in the context of diversity. Standard 3 centers on diverse learners, focusing on understanding how individuals differ in their approaches to learning and on the creation of appropriate instruction. The core concept of this standard is based on a beginning teacher's ability to understand, appreciate, and address individual differences in learning concepts such as physical disability, and culturally diverse backgrounds. This standard especially seeks to diversify instructional approaches through the design of learning environments that meet the learners' academic and social development needs.

Overall, successful physical education teachers in the culturally diverse school setting (e.g., urban schools) tend to maintain high expectations for student accomplishment, provide the best possible learning environments, and implement activities that aid increased student involvement (Ennis, et al., 1997; Henninger, 2007; McCaughtry, Barnard, Martin, Shen, \& Kulinna, 2006). The review of literature on physical education teachers' knowledge and skills in multicultural education are organized into two categories: research relevant to pre-service teachers and in-service teachers.

\section{Research Finding}

What Students Like About Physical Education. In reviewing the results of the survey on student motivation, I discovered that across all ethnic backgrounds, students enjoy physical education because they enjoy being with their friends. Physical education has the most potential above all other subjects for students to make new friends, be with their old friends, and develop interpersonal skills that will last a lifetime. As a result, it is important for teachers to develop a non-threatening climate where respect for all individuals regardless of ethnicity or athletic ability is fostered.

The second highest ranked reason for liking P.E. is that students find P.E. to be an easy "A." While some may cringe at the thought that a 
class would be "easy," I believe students need to balance their academic work with a class that is challenging yet accommodating to students of all language and cognitive abilities. One interesting perception is that the Hispanic students rated that reason second from the last. They felt that getting a break from the classroom and competition were more desirable outcomes from physical education class. Another interesting observation was that African-American and mixed students all ranked getting in shape as the least of their reasons for liking physical education. This can be interpreted as they aren't concerned with or cognitive of their physical condition, or that they enjoy physical education so much they don't identify that as a result of their participation in P.E. class.

What Students Don't Like About Physical Education. While most any teacher's ultimate desire for his or her students is to have high motivation, it's inevitable that students will have reasons for being unmotivated. My students at Falls Church High School unanimously determined that wearing a P.E. uniform for class along with the way physical education affects their appearance for the remainder of the school day were the overwhelmingly popular reasons why they aren't motivated or don't like physical education. Of these two reasons, one can reasonably be addressed in favor of students' opinions. While my own personal philosophy on P.E. uniforms has changed from year to year, I am ready to test how much a change in this policy would affect the success and motivation of my students. While I won't discuss the pros and cons of requiring a P.E. uniform in this article, the issues surrounding uniforms range from cultural to hygienic, management, and lastly economic concerns.

The second major problem my students have with physical education is that their appearance is altered for the remainder of the school day. This is especially true for the girls who generally require much more time to aesthetically "recover" from a "sweaty" activity that messes up their hair. While we allow students an average of ten minutes to change clothes following class, for many students the damage is irreparable. Students don't like to shower because they feel embarrassed to do so in a group setting. Most schools do not have private shower settings or the funds to support 
such an environment. Some feel that they do not have enough time to shower. As a teacher, I don't see any easy or conceivable solution to fully resolving this concern. Additional research specifically designed to address this issue may me helpful in the future.

While this was not a top issue for all ethnicities, most physical education classes across the United States have an average of 35 - 40 students per class. With so many students to instruct, it is difficult for teachers to give students of differing abilities individualized instruction. Many times lack of equipment or small facilities detract from a teacher's desired outcome to have all students on task and participating at all times. At times, optimal supervision is compromised which can in turn result in safety issues. This has definitely been a concern among teachers in my physical education department at Falls Church and our students as indicated in the survey. Although creative planning and preparation can help remedy the problem, this will continue to be an issue in the realm of physical education for all persons involved.

\section{E. Discussion and Reflections}

\section{Values Developed Through Physical Education}

Students develop many values as a result of participation in a physical education program. Regardless of ethnicity, my students felt that physical education should be fun and entertaining. This goes hand in hand with the fact that what students enjoyed most about physical education is that they get to be with their friends. Caucasian and Asian students felt that P.E. should help students develop an interest in whatever activity is being taught versus Black, Latino and student of mixed backgrounds who were more concerned with developing teamwork. I can see a cultural connection with this perception. Caucasian and Asian students seem to work better as individuals in general while the other groups, particularly Latinos, have a history of being group or team motivated.

\section{Preferred Physical Activities}

When it comes to sports and other physical activities many people have stereotypes about which ethnic groups enjoy which sports, myself 
included. Sports are strongly related to culture. So it seems only appropriate that those stereotypes hold true more often than not. However, as a result of this survey some perceptions are dispelled. For example, when asked to rank their top five favorite activities from a list of 40, Caucasian students ranked swimming as their number one activity. Baseball/Softball, often considered the "all-American" pastime, was not even on their top five list. Asian students chose tennis as their favorite activity, but included in the list basketball, volleyball and swimming, sports that are typically valued higher by Caucasian students. My theory behind their preferences for these sports is that these students (mainly Vietnamese, Korean, or other immigrants) are trying to assimilate into American culture and by attempting to learn and become skilled at these activities they acculturate into society with more ease. Black students (most American-born) held true to their stereotype somewhat, choosing basketball as their favorite activity.

However, there are a few surprises here. These students also indicated swimming, tennis and weight training among their favorites. Latinos too were loyal to soccer as their number one sport, but also favored tennis and swimming, two sports not typically strong in their native countries. I really had no preconceived thought about which activities my students of mixed ethnicities would favor. But I was surprised to see that among their favorite activities, dance was listed fourth. I would like to do further research to find out what type of dance they enjoy. This is one activity that our P.E. department has not included in our curriculum.

\section{Least Preferred Physical Activities}

As with all curriculum, there are some activities that students are bound to not enjoy, P.E. is no exception. When students don't enjoy an activity, they are less motivated to perform well despite the external or internal rewards. In physical education, the curriculum has such a wide base that it is easy for a teacher to assess the needs and desires of his or her students then teach accordingly. This was the main motivation behind 
conducting this research. I want my students to find success in physical education and knowing their dislikes will help me address these concerns. I discovered there are not many differences across cultures concerning activities the students don't enjoy. One difference did stand out with running. My Asian students were the only group of students who did not indicate running as their five least favorite activities.

All students regardless of ethnic background listed golf as one of their least favorite activities, with whites, blacks and Hispanic students list that is their number one disliked activities. I think one reason for such a strong response with golf is that when the survey was administered, all students were in their first days of the golf unit. Most of the students had never held a golf club before, so I think it was more a fear of the unknown. Since this writing, I've had several students comment that they enjoyed the golf unit and are interested in trying out for the team. One girl told me that before our unit, she considered golf to be an "old person's sport" but soon realized it was an activity she enjoyed.

One other activity that was high on the list of dislikes was aerobics. My black students were the only group of students who didn't list aerobics as their five least favorite activities. However, there is one disclaimer here too. If I break up the results based on gender, girls enjoy aerobics while guys hate it. It was not so much of a cultural difference as it was a difference between genders. This leads me to believe that while Title IX has brought many improvements to physical education, gender differences should be taken into account when considering curriculum for the year.

\section{F. Conclusion.}

The global trends on human migrations point to a growing diverse student population in schools in the United States. This project has revealed much insight for me into my students' perceptions and motivation in physical education. Like most educators, I wanted to discover ways to improve physical education for all students across cultures. This research has been a jumping off point to review and discuss issues dealing with physical education that are personal to my students. 


\section{Bibliography}

Banks, J. A. (2002). An introduction to multicultural education (3rd ed.). Boston: Allyn and Bacon.

Butt, K. \& Pahnos, M. (1995). Why We Need a Multicultural Focus in Our Schools. Journal of Physical Education, Recreation \& Dance. 48-53.

Cushner, K., McClelland, A., \& Safford, P. L. (2006). Human diversity in education : an integrative approach (5th ed.). Boston: McGraw-Hill

DeSensi, J. (1995). Understanding Multiculturalism and Valuing Diversity: A Theoretical Perspective. Quest, 34-43.

Duda, J. (1996). Maximizing Motivation in Sport and Physical Education among Children and Adolescents: The Case for Greater Task Involvement. Quest, 290-302.

Ennis, C. D., Cothran, D. J., Davison, K. S., Loftus, S. J., Owens, L., Swanson, L., et al. (1997). Implementing curriculum within a context of fear and engagement. Journal of Teaching in Physical Education, 17, 52-71.

Grant, A. C., Elsbree, R. A., \& Fondrie, S. (2004). A decade of research on the changing terrain of multicultural education research. In J. A. Banks, \& C. A. McGee-Banks, Handbook of research on multicultural education (pp. 184-207). San Francisco: Jossey-Bass.

Henninger, M. (2007). Lifers and troupers: Urban physical education teachers who stay. Journal of Teaching in Physical Education, 26, 125-144.

Lvina, E. (2015). The Role of Cross-Cultural Communication Competence: Effective Transformational Leadership Across Cultures. Jurnal Ilmiah Peuradeun, 3(1), 1-18.

McCaughtry, N. Barnard, S., Martin, J., Shen, B., \& Kulinna, P. H. (2006). Teacher's perspectives on the challenges of teaching physical education in urban schools. The student emotional filter. Research Quarterly for Exercise and Sport, 77, 486-497

National Association for Sport and Physical Education. (2003a). Moving into the future: National standards for physical education (2nd ed.). Reston, VA: Author.

National Association for Sport and Physical Education. (2003b). National Standards for Beginning Physical Education Teachers (2nd Edition ed.). Oxon Hill, MD: Author. 
Rong, X. L., \& Preissle, J. (2009). Educating immigrant students in the 21st century: what educators need to know (2nd ed.). Thousand Oaks, Calif.: Corwin Press.

Santrock, J. W. (2001). Educational psychology. New York: McGraw Hill.

Smith, Y.R. Issues and Strategies for Working with Multicultural Athletes." Journal of Physical Education, Recreation and Dance. Volume 62 (3), 39-44.

Sparks, W. \& Verner, E. Intervention Strategies in Multicultural Education: A Comparison of Pre-Service Models." ERIC ED323179.

Sparks, W. G., Butt, L. K., \& Pahnos, M. (1996). Multicultural education in physical education: A study of knowledges, attitudes and experiences. The Physical Educator, 53, 73-8

Swisher, K. \& Swisher, C. (1986). A Multicultural Physical Education Approach. An Attitude." Journal of Physical Education, Recreation \& Dance. 35-39.

Tannehill, D. and Zakrajsek, D. (1993). Student Attitudes toward Physical Education: A Multicultural Study." Journal of Teaching in Physical Education, 78-84.

Yusoff, M. Z. M., \& Hamzah, A. (2015). Direction of Moral Education Teacher To Enrich Character Education. Jurnal Ilmiah Peuradeun, 3(1), 119-132.

ZA, T. (2014). Islamic Studies dalam Pendekatan Multidisipliner (Suatu Kajian Gradual Menuju Paradigma Global). Jurnal Ilmiah Peuradeun, 2(2), 211-234. 